\title{
COMPUTED TOMOGRAPHIC EVALUATION OF PARANASAL SINUS AND PATHOLOGIES
}

Vijay Prabhu R¹, M. Adaikappan², S. Sethurajan³

\section{HOW TO CITE THIS ARTICLE:}

Vijay Prabhu R, M. Adaikappan, S. Sethurajan. "Computed Tomographic Evaluation of Paranasal Sinus and Pathologies". Journal of Evolution of Medical and Dental Sciences 2015; Vol. 4, Issue 33, April 23;

Page: 5741-5747, DOI: 10.14260/jemds/2015/839

ABSTRACT: AIM: To assess the role of computed tomography in the evaluation of diseases involving paranasal sinuses and to correlate it with clinical diagnosis. METHODOLOGY: Patients with symptoms involving paranasal sinuses were evaluated by clinical and CT (Both axial and coronal sections) findings for management of patients. RESULTS: CT diagnosis had higher sensitivity, specificity, positive predictive value and negative predictive value in diagnosing anatomic variants of PNS, chronic sinusitis, sinonasal polyps and other lesions in comparison to clinical diagnosis. However sensitivity of CT was not so high in diagnosing fungal sinusitis as seen with other lesions. But involvement of the bone by PNS lesions was always demonstrasted by the CT, which is the standard imaging modality to demonstrate it accurately. CONCLUSION: Pathological conditions of PNS are common and have a varied presentation in all the age groups. These are difficult to diagnose accurately on conventional plain films. CT imaging provides detailed information regarding involvement, location, extent of paranasal sinus diseases accurately and is an excellent alternatives to standard radiographs.

KEYWORDS: Computed Tomography, Para Nasal Sinuses, Normal Variants, Fungal Infection, Neoplasms.

INTRODUCTION: Diseases of paranasal sinuses include wide spectrum ranging from inflammation conditions to neoplasms both benign and malignant. Plain film is inaccurate and inadequate in diagnosis of various pathologies of paranasal sinuses. Imaging of PNS has progressed from the realm of conventional radiographs into the realm of computed tomography (CT) and magnetic resonance imaging (MRI). Technological advances in these two modalities have provided more precise differential diagnosis and greater details about the anatomic extent of the diseases of PNS:

- CT plays an important diagnostic role in patients with sinonasal disease and determines the treatment. A complete axial and coronal CT scans series provides an excellent and comprehensive evaluation of PNS.

- CT excels over MRI at evaluating fine bone details, assessment of fibro osseous lesions of PNS. CT plays an important role in pre-operative evaluation of patients considered for functional endoscopic sinus surgery (FESS) and screening sinus CT (SSCT). CT determines the distribution, extent of disease and detection of anatomic variations (like septal deviation, spur formation, concha bullosa, paradoxical middle turbinate, etc.) that may place the patients at increased risk for intra operative and post-operative FESS complications and thereby reduces the morbidity and mortality of patients.(1)

PITFALLS IN CT: Due to its complex projections, artefacts induced by very high density structures around PNS, by the patient movement, limited soft tissue resolution and even radiation exposure in CT examinations limits frequent usage in children and pregnant women. 


\section{REVIEW ARTICLE}

For these reasons, MRI is also considered as imaging modality in some conditions.

MATERIALS AND METHODS: A total of 50 patients of whom 17 were males and 33 females were studied. Age group varied from 10 to 60 years. Patients were selected from out patient's clinics and wards of department of otolaryngology RMMCH Chidambaram. Patients were selected on the basis of their symptoms and clinical findings suggestive of a lesion involving the paranasal sinus such as head ache, nasal obstruction, nasal discharge, anosmia, postnasal discharge, epistaxsis. All the examination were performed on a PHILIPS MX 8000 computed tomographic scanner.

Patients was scanned in two sections one axial, patient was placed in supine position and scan plane was oriented parallel to hard palate and extended from hard palate upto upper margin of frontal sinus. Coronal sections was performed by placing the patient in prone position and scan plane was oriented perpendicular to hard palate and extended from posterior margin of sphenoid sinus upto anterior margin of frontal sinus.

Thickness of the slices for both axial and coronal sections is $5 \mathrm{~mm}$ and $3 \mathrm{~mm}$ were taken at osteomeatal unit on coronal sections, Tube current $440 \mathrm{mAs}$, Tube voltage is $120 \mathrm{kV}$, scan time is 2.7 sec. IV contrast agent (Omnipaque 350) used if indicated at a calculated dose of $300 \mathrm{mg} / \mathrm{kg}$ weight as a single intravenous bolus injection after serum creatinine level was estimated. Contrast enhanced lesion visualized in soft tissue window using raw data process.

Reconstructed images were viewed using a window length of 400 and a wide window of maximum possible. The features evaluated were site, size, characterizations, involvement of adjacent structures, vascular involvement.

RESULTS: Our study included 50 patients in the age group of 10 to 60 years with the mean age of 30 years with a female: male 1. 9:1 with greater number of patient in age group 20-40 years. Most of the patients had headache $56 \%$, followed in decreasing order by nasal discharge $52 \%$, nasal obstruction $34 \%$ and epistaxis $8 \%$. Most commonly diseased sinus is maxillary sinus $86 \%$, ethmoid sinus $80 \%$, frontal sinus $54 \%$, sphenoid sinus $48 \%$. Deviated nasal septum is noted in 24 patients with common towards to right side $26 \%$ than left side $22 \%$. Concha bullosa unilateral is noted in $11(22 \%)$ of patient and bilateral concha bullosa is noted in $3(6 \%)$ patients. $56 \%$ of cases had sinusitis, polyp was found in $32 \%$, fungal sinusitis $8 \%$, inverted papilloma $12 \%$. During FESS, 4 patients were found to have bone involvement in form of erosion or destruction, all 4 patients was detected to have bone involvement in CT.

Best comparison is observed between CT and final diagnosis.

DISCUSSION: CT has replaced conventional radiographs as imaging modality of choice for assessment of paranasal disease. CT determines exquisite details of anatomy, anatomic variants, distribution and extent of disease.

\section{ANATOMIC VARIANTS:}

Nasal Septum(2): Nasal septum may be focally deviated inferiorly at the chondrovomeral junction or have a more broad based curvature. Septal spurs are frequently encountered in association with septal deviation and if prominent may also make surgical access difficult and narrow the middle meatus or ethmoidal infundibulum. Pneumatised septum is usually due to extension of air from the sphenoid sinus or crista galli and is usually not significant but may marrow the sphenoethmoidal recess (SER). 
Concha Bullosa: Pneumatisation of the inferior bulbous portion of the turbinate. If the pneumatisation is above the level of OMU complex, it is called lamella cell.(3,4)

Paradoxical Middle Turbinate Turn: The middle turbinate may have a lateral convexity. If is large it may impair access to OMU.

Maxillary Septum: It is a fibrous or bony and often extends from the infraorbital canal to the lateral wall and if not recognized may lead to inadequate drainage of the antrum.(5)

Sphenoid Septum: It is the presence of multiple septa within the sphenoid than the main septa. It is stated that multiple accessory septa are seen more commonly on the right side of main septa. (6)

Inflammatory Polyp: These are pendunculated out growths of edematous mucosa, which is cellular and covered by normal epithelium, arising from paranasal sinus. It is mostly related to hypersensitivity states, non-allergic asthma and cystic fibrosis.(7)

Mucoceles: These are most common expansile lesions of paranasal sinus. It is airless mucoid filled, expanded paranasal sinuses. It is caused due to inflammatory, allergic, trauma, osteoma, complications of previous surgery. ${ }^{(8)}$

Fungal Infection: The most common fungal disease are mucormycosis, histoplasmosis, candidiasis, aspergillosis. The causative organisms are invasive and tend to spread rapidly from the nasal cavity to the paranasal sinuses. They have propensity for involving the blood vessels, orbits, cavernous sinuses, ophthalmic veins.

\section{BENIGN NEOPLASM(9):}

Papilloma: These are commonest epithelial tumour in the paranasal sinus and lateral wall of nasal cavity arising from scheneiderian membrane, which is lining respiratory epithelium of nose and paranasal sinuses. Usually they are bulkier and firmer than nasal polyps, but lack its translucency. They grow into architectural pattern 1. Papillary and exophytic 2. Inverted, with an inwardly invaginating epithelial growth into underlying stroma.

Adenoma: These are capsulated, usually symptomless, but if they arise from the lateral wall of the nose it produces nasal obstruction.

Angiofibroma: This tumour is highly vascular and non-encapsulated polypoid mass that is histologically benign but highly aggressive. The triad of epistaxis, nasal obstruction and presence of a nasopharnygeal mass strongly indicates an angiofibroma. It occurs mostly in pre-pubescent or pubescent males. Intracranial extension is seen in some cases.

Malignant Tumours of Paranasal Sinuses: Malignant tumours of paranasal sinuses are rare and $50-65 \%$ of nasal malignancies arise within maxillary sinus. Squamous cell carcinoma accounts for $80 \%$ of all malignancies. Other neoplasm in this region includess lymphoma, melanoma, 
plasmacytoma and others. The lethality and poor prognosis of carcinoma of the sinuses are directly related to early silence or misleading signs and symptoms of these cancers, which allow extension before discovery. The carcinomas of sinuses do not show significant evidence of their pressure until they have broken out of sinus of origin. Most of the sinus carcinoma will manifest with invasion through at least one wall of the involved sinus.

\begin{tabular}{|c|c|c|}
\hline AGE & NO. OF CASES & \% CASES \\
\hline $5-10$ & 1 & 2.00 \\
\hline $11-20$ & 7 & 14.00 \\
\hline $21-30$ & 19 & 38.00 \\
\hline $31-40$ & 11 & 22.00 \\
\hline $41-50$ & 7 & 14.00 \\
\hline $51-60$ & 3 & 6.00 \\
\hline$>60$ & 2 & 4.00 \\
\hline \multicolumn{3}{|c|}{ Table1: AGE CHART } \\
\hline
\end{tabular}

MEAN AGE: 30 years

Commonest Age Group: 21-40 years.

No. of Females: 33(66\%).

No. of Males: 1 (34\%).

\begin{tabular}{|c|c|c|}
\hline SEX & NUMBER OF PATIENT & PERCENTAGE \\
\hline FEMALE & 33 & $66 \%$ \\
\hline MALE & 17 & $34 \%$ \\
\hline TOTAL & $\mathbf{5 0}$ & $\mathbf{1 0 0 ~ 0 0}$ \\
\hline \multicolumn{3}{|c|}{ Table 2: SEX DISTRIBUTION } \\
\hline
\end{tabular}

Majority of cases were females 66\% (33). Males accounted for 34\% (17).

Female: Male ratio is 1. 9:1

\begin{tabular}{|c|c|c|}
\hline CHIEF COMPLIANTS & NO. OF PATIENTS & PERCENTAGE \\
\hline HEAD ACHE & 28 & $56 \%$ \\
\hline NASAL DISCHARGE & 26 & $52 \%$ \\
\hline NASAL OBSTRUCTION & 17 & $34 \%$ \\
\hline EPISTAXIS & 4 & $8 \%$ \\
\hline
\end{tabular}

In our study, most of the patients had headache (56\%), nasal discharge (52\%), nasal obstruction (34\%), epistaxis (8\%). 
REVIEW ARTICLE

\begin{tabular}{|c|c|c|}
\hline SINUS & NUMBER & PERCENTAGE \\
\hline MAXILLARY & 43 & $86 \%$ \\
\hline ETHMOID & 40 & $80 \%$ \\
\hline FRONTAL & 27 & $54 \%$ \\
\hline SPHENOID & 24 & $48 \%$ \\
\hline \multicolumn{2}{|r|}{ Table 4: SINUS DISEASED } \\
\hline
\end{tabular}

In this study most common diseased sinus is maxillary sinus (86\%), following decreasing order Ethmoid sinus (80\%), Frontal sinus (54\%) and Sphenoid sinus (48\%).

\begin{tabular}{|c|c|c|}
\hline DNS & NUMBER & PERCENTAGE \\
\hline NO DNS & 26 & $52 \%$ \\
\hline TO RIGHT & 13 & $26 \%$ \\
\hline TO LEFT & 11 & $22 \%$ \\
\hline
\end{tabular}

Table 5: ANATOMIC VARIANTS

Deviated nasal septum was seen in 24 patients with more common in right side $(26 \%)$ and left side $(22 \%)$.

\begin{tabular}{|c|c|c|}
\hline CONCHA BULLOSA & NUMBER & PERCENTAGE \\
\hline NO & 36 & $72 \%$ \\
\hline UNILATERAL & 11 & $22 \%$ \\
\hline BILATERAL & 3 & $6 \%$ \\
\hline \multicolumn{3}{|c}{ Table 6} \\
\hline
\end{tabular}

Concha bullosa is noted in 14 patients with more common in unilateral (22\%) and bilateral $(6 \%)$.

\begin{tabular}{|c|c|c|c|c|}
\hline \multirow{2}{*}{ FINDINGS } & \multicolumn{2}{|c|}{ CT } & \multicolumn{2}{c|}{ FINAL DIAGNOSIS } \\
\cline { 2 - 5 } & NUMBER & PERCENTAGE & NUMBER & PERCENTAGE \\
\hline SINUSITIS & 28 & $56 \%$ & 27 & $54 \%$ \\
\hline POLYP & 16 & $32 \%$ & 16 & $32 \%$ \\
\hline FUNGAL SINUSITIS & 4 & $8 \%$ & 5 & $10 \%$ \\
\hline $\begin{array}{c}\text { NEOPLASM (BENIGN \& } \\
\text { MALIGNANT) }\end{array}$ & 6 & $12 \%$ & 6 & $12 \%$ \\
\hline \multicolumn{2}{|r}{ Table 7: COMPARISON OF CT AND FINAL DIAGNOSIS } \\
\end{tabular}

Best comparison is seen between CT and final diagnosis. 


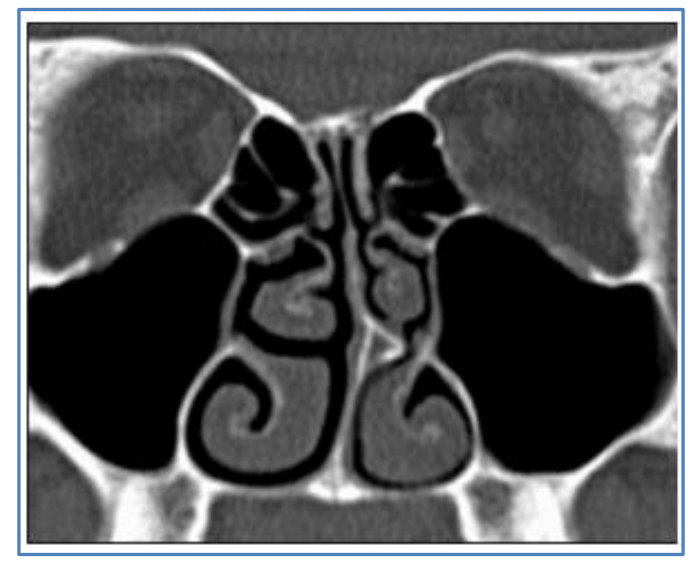

FIGURE 1: CT PNS Coronal section showing deviated nasal septum toward left side

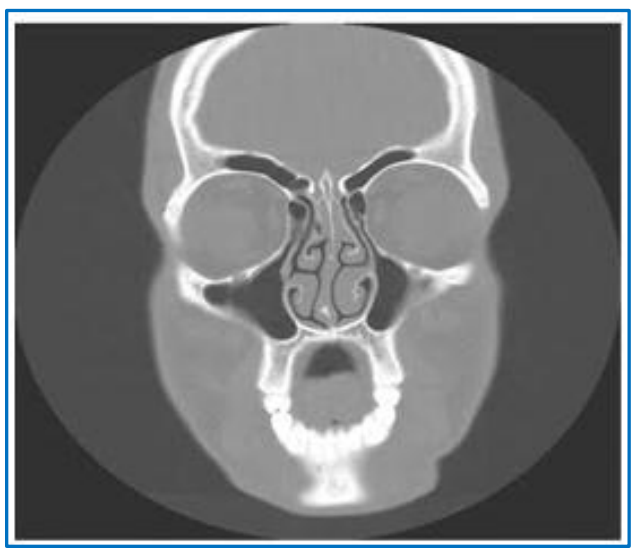

FIGURE 3: CT PNS Coronal section showing paradoxical turn of middle turbinates

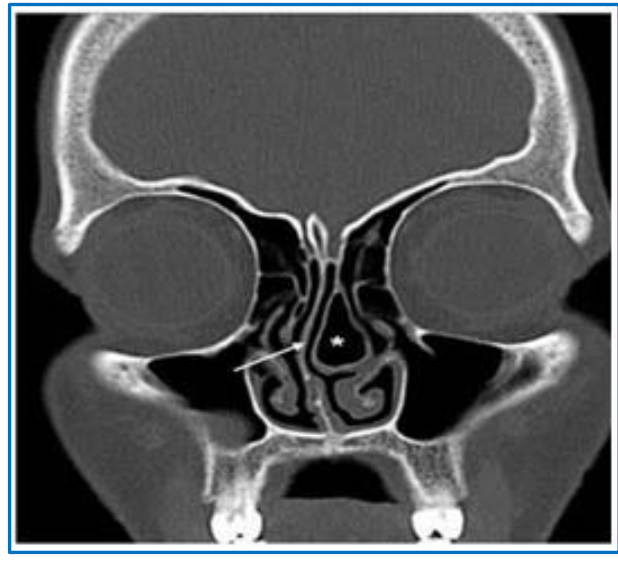

FIGURE 2: CT PNS Coronal section showing left concha bullosa with DNS

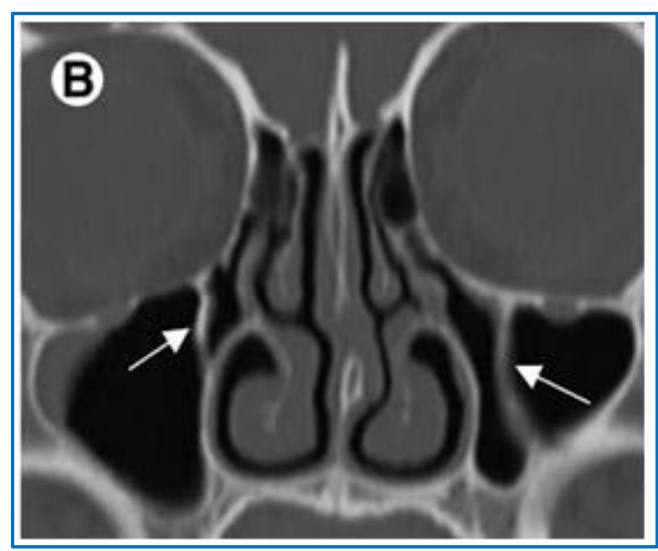

FIGURE 4: CT PNS Coronal section showing a bony septation within maxillary antrum
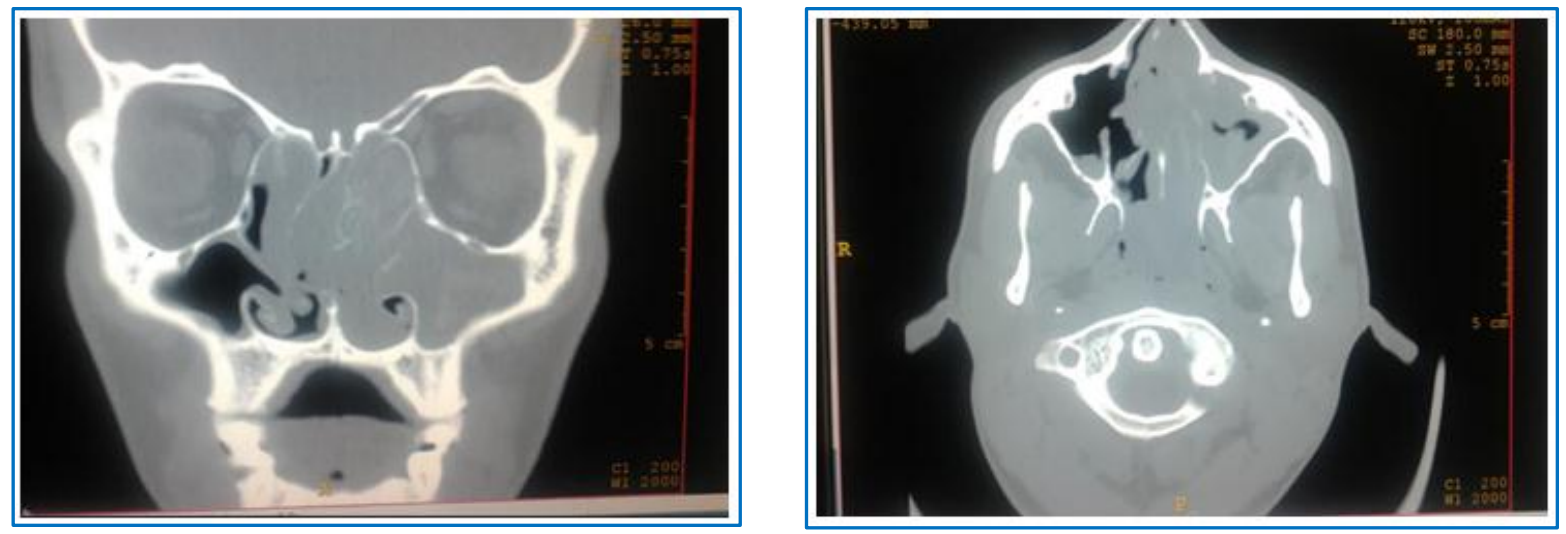

FIGURE 5: CT PNS Axial and Coronal section section left antrochoanal polyp with nasopharyngeal 


\section{REFERENCES:}

1. Scuderi A J, Harnsberger H R, Boyer R S. Pneumatization of the paranasal sinuses: normal features of importance to the accurate interpretation of CT scans and MR images. AJR Am J Roentgenol. 1993; 160:1101-1104.

2. Lerdlum S, Vachiranubhap B. Prevalence of anatomic variation demonstrated on screening sinus computed tomography and clinical correlation. J Med Assoc Thai. 2005; 88 suppl 4: 110115.

3. Stallman J. The incidence of concha bullosa and its relationship to nasal septal deviation and paranasal sinus disease's. American Journal of Neuroradioloy. 2004; 25:1613-1618.

4. Zinreich S. J, Mattox DE, Kennedy DW. Concha Bullosa: CT Evaluation. J Comput Assist Tomogr. 1988; $12:$ 778-784.

5. Ariji Y., Ariji E., Yoshiura K., Kanda S. 1996. Computed tomographic indices for maxillary sinus size in comparison with the sinus volume. Dentomaxillofac. Radiol. 25: 19-24.

6. Sirikci A, Bayazit Y A, Bayram M, Mumbuc S, Gungor K, Kanlikama M. Variations of sphenoid and related structures. Eur Radiol. 2000; 10:844-848.

7. Bolger WE, Butzin CA, Parsons DS. Paranasal sinus- Bony anatomic variation and mucosal abnormalities: CT analysis for endoscopic sinus surgery Laryngoscope Jan 1991; 101:56-65.

8. William EB. Paranasal sinus Bony Anatomic variations and mucosal abnormalities: CT analysis for endoscopic sinus surgery. Laryngocope. 1991; 101: 56-64.

9. Zinreich S, Albayram S, Benson M, Oliverio P. The ostiomeatal complex and functional endoscopic surgery. In: Som P, ed. Head and neck imaging. 4th ed. St Louis: Mosby, 2003:149173.

\section{AUTHORS: \\ 1. Vijay Prabhu R. \\ 2. M. Adaikappan \\ 3. S. Sethurajan}

\section{PARTICULARS OF CONTRIBUTORS:}

1. Second Year Resident, Department of Radiodiagnosis, Rajah Muthiah Medical College, Chidambaram.

2. Professor \& Head, Department of Radiodiagnosis, Rajah Muthiah Medical College, Chidambaram.

3. Assistant Professor, Department of Radiodiagnosis, Rajah Muthiah Medical College, Chidambaram.

FINANCIAL OR OTHER COMPETING INTERESTS: None

\section{NAME ADDRESS EMAIL ID OF THE} CORRESPONDING AUTHOR:

Dr. Vijay Prabhu R, No. 1, Golden Villa, Vijay Grand Garden, Ritish Venue, Mariyappa Nagar, Chidambaram-608002.

E-mail: rvijayprabhu@gmail.com

Date of Submission: 23/02/2015. Date of Peer Review: 24/02/2015. Date of Acceptance: 06/04/2015. Date of Publishing: 22/04/2015. 